\title{
The Development of Subjective Group Dynamics: Children's Judgments of Normative and Deviant In-Group and Out-Group Individuals
}

\author{
Dominic Abrams, Adam Rutland, and Lindsey Cameron
}

\begin{abstract}
A developmental model of subjective group dynamics suggests that social identity is sustained first by intergroup biases and later by intragroup biases. In this study 476 English children 5 to 11 years old evaluated the English and German soccer teams, and judged in-group or out-group members whose attitudes toward the teams was normative versus antinormative. Children of all ages expressed intergroup bias. Differential evaluation against in-group deviants and in favor of out-group deviants strengthened with age. Understanding of targets' relative acceptability (differential inclusion) among in-group and out-group members mediated the effects of age and intergroup bias on intragroup bias. Identification with the in-group moderated the effects only among older children.
\end{abstract}

The present research investigated developmental changes in children's intergroup bias and judgments of in-group and out-group members who conform to or deviate from the norms of those groups. Intergroup biases are known to emerge relatively early in childhood (see Aboud, 1988; Bigler, 1995; Bigler \& Liben, 1992; Nesdale, 2001; Powlishta, Serbin, Doyle, \& White, 1994; Yee \& Brown, 1994). Research into children's intergroup attitudes has frequently employed measures of group preference, whereby children are required to evaluate targets that represent the whole social group (e.g., a boy vs. a girl; see reviews by Aboud, 1988; Aboud \& Amato, 2001; Katz, 1976; Nesdale, 2001). This methodology does not distinguish between evaluations of individual in-group and out-group members and evaluations of the groups as a whole. Developmental research suggests that in addition to understanding group membership, children begin to attend to what is normative and deviant in their group during social reasoning about inclusion and exclusion (Killen, Crystal, \& Watanabe, 2002; Killen \& Stangor, 2001). However, relatively little is known about the development of children's direct judgments of specific normative and deviant members of social groups (Ruble, Alvarez, Bachman, \& Cameron, in press). The aim of the present research was to investigate children's intergroup judgments and differentiated evaluations of individual group members in terms of their adherence to group norms.

Dominic Abrams, Adam Rutland, and Lindsey Cameron, Department of Psychology, University of Kent, UK.

Correspondence concerning this article should be addressed to Dominic Abrams, Department of Psychology, University of Kent, Canterbury CT2 7NP, England. Electronic mail may be sent to D.Abrams@kent.ac.uk.
Our research was set in the highly competitive and involving intergroup context of the 2002 World Cup Soccer Finals. In particular, our focus was on an explicit in-group versus out-group comparison known to be salient among English schoolchildren (i.e., England vs. Germany; see Barrett \& Short, 1992; Rutland, 1999). English children evaluated the English and German soccer teams, and judged a normative and deviant soccer fan from either the in-group or out-group. The normative target expressed normative attitudes by favoring their own group. The attitudes of the deviant target were counternormative (i.e., disloyal) because they evaluated both the in-group and out-group positively. To examine whether there are developmental changes in reactions to normative and deviant group members, we examined responses from children 5 to 11 years old. This age range was chosen because evidence suggests that between these ages children develop the ability to attend to individuating information and multiple classifications (e.g., Bigler, 1995; Doyle \& Aboud, 1995), a necessary requirement for intragroup differentiation.

Cognitive-developmental theory (cf. Aboud, 1988; Katz, 1976; Lambert \& Klineberg, 1967) was developed to explain children's group attitudes in contexts less explicitly competitive than the one used within this study. Nevertheless, relevant to our concerns, cognitive-developmental theory suggests a given relationship between intragroup and intergroup judgments. This theory holds that with age children cease to focus only on group differences, and they become capable of making social judgments also on the basis of unique characteristics of

(C) 2003 by the Society for Research in Child Development, Inc. All rights reserved. 0009-3920/2003/7406-00017 
an individual. Consequently with age, the availability of information about individuals' characteristics should help reduce intergroup biases. Specifically, Aboud's (1988) theory of social-cognitive development holds that there is a developmental sequence in which the child's focus of attention shifts from self to group (i.e., intergroup) and finally to individual (i.e., intragroup) characteristics. At this final stage, children may still express more positive evaluations of some individuals over others, but the criterion for judgment will not be solely that of group membership (see Aboud, 1988, pp. 23-25).

A significant body of research on adults has examined how deviant members of in-groups and out-groups are evaluated (e.g., Abrams, Marques, Bown, \& Henson, 2000; Marques, Abrams, Pàez, \& Martinez-Taboada, 1998, Marques, Abrams, \& Serôdio, 2001). The findings of this adult research suggest a less sequential and more dynamic relationship between intragroup and intergroup judgments. Adults commonly express bias in favor of their ingroups and in favor of typical or normative in-group members over out-group members. However ingroup bias appears to be eliminated or even reversed when deviant group members are judged (Abrams, Marques, Randsley de Moura, Hutchinson, \& Bown, in press; Marques \& Pàez, 1994). For example, Marques, Yzerbyt, and Leyens (1988) found that likable in-group members were favored over likable out-group members, but unlikable out-group members were favored over unlikable in-group members, a phenomenon they labeled the black sheep effect.

The black sheep effect and related findings have been explained using the subjective group dynamics (SGD) model (Abrams et al., 2000; Marques et al., 1998). The term subjective group dynamics describes the psychological dynamics that affect judgments of groups and their members when social identity is relevant (see Marques, Abrams, Pàez, \& Hogg, 2001; Abrams et al., in press, for details). Group dynamics of small face-to-face groups include efforts to constrain and control deviants to maintain consensus surrounding group norms (e.g., Schachter, 1951; see also Levine, 1989). The SGD model assumes that an analogous process occurs subjectively even when the groups are social categories and when the individuals do not have interpersonal contact. The model adds a further level to these dynamics, namely, the intergroup context, and the premise from social identity theory (SIT; e.g., Tajfel, 1981; Tajfel \& Turner, 1986) that people are motivated to sustain a positive social identity (i.e., identification with self-inclusive social categories).
Based on group dynamics research and SIT, the SGD model holds that group members strive to attain both positive in-group distinctiveness and support for in-group norms within groups. The former process implies a general preference for the in-group over the out-group, and the latter process involves vigilant attention to individual group members, both to detect possible dissent from norms and to respond in a way that upholds the in-group's norms. The crucial comparison within groups is between individuals who appear to uphold the group's norms and those who do not. In an intergroup context, the relevant norms to be upheld and rejected are those of the in-group and out-group, respectively. Therefore, the process of intragroup differentiation responds dynamically to the comparison groups that are relevant within a social context. Consequently, the same deviant behavior may be evaluated differently depending on whether it is exhibited by an in-group or an out-group member and depending on whether it implies support or rejection of the norms for each group. Because group members must attain both intergroup and intragroup differentiation to achieve subjectively valid intergroup differences, the SGD model holds that the two processes should be positively related. The consequence is that people who show the greatest biases in favor of their own group are also likely to differentiate most strongly between normative and deviant members within groups, for example, showing a stronger black sheep effect (e.g., Abrams et al., 2000; Abrams, Marques, Bown, \& Dougill, 2002).

Based on cognitive-developmental theory and research it is reasonable to expect that, as they get older, children attend more closely to individuating characteristics of group members (Bigler, 1995; Black-Gutman \& Hickson, 1996; Doyle \& Aboud, 1995; Katz, Sohn, \& Zalk, 1975, Martin, 1989). However, bearing in mind the SGD model, we believe this may not always be at the expense of, or detriment to, category-based judgment. Instead, children's developing ability to engage in multiple classifications and perceive within-group differences may augment, rather than inhibit, their use of social category memberships for making judgments about individuals.

Some existing evidence (e.g., Bigler, 1995; Doyle \& Aboud, 1995) leads us to expect that SGD will operate increasingly with age. The use of intragroup differentiation to sustain the subjective validity and legitimacy of in-group norms requires the ability to attend to individuating information and multiple classifications. These social cognitive skills are known to develop in middle childhood. From the 
ages of approximately 7 to 8 years, children have made important social cognitive transitions from judgments based on a few primarily physical categories (e.g., sex, hair color) to judgments formulated using a multitude of psychological categories (e.g., intelligent, altruistic, friendly). This shift with age from physical to psychological descriptors is evident within the developmental literatures on person perception (e.g., Barenboim, 1978, 1981; Livesley \& Bromley, 1973; Peevers \& Secord, 1973), social perspective taking (Selman, 1971, 1980), and ethnic perspective taking (Quintana, 1998, 1999). Other studies suggest that around 9 years children no longer perceive people primarily through global descriptors (i.e., boy or girl) but also begin to acknowledge individual differences in dispositional characteristics (Alvarez, Ruble, \& Bolger, 2001; Ruble \& Dweck, 1995).

In line with the preceding evidence, our developmental SGD model holds that, as children get older they become more able to recognize that deviance constitutes a departure from norms that other group members would want to preserve (i.e., that it is a variation between individuals that is relevant to their group membership). Once children are able to recognize these potential group dynamics they can engage in evaluative intragroup differentiation. They will then also be able subjectively to sustain valued differences between in-groups and out-groups by expressing positive evaluations of individuals from both the in-group and the outgroup who provide relative support for in-group categories.

A limited number of studies have asked children to evaluate or make judgments relating to individual members of social groups (Abrams, Rutland, Cameron, \& Marques, 2003; Berndt \& Heller, 1986; Biernat, 1991; Martin, 1989; Serbin \& Sprafkin, 1986). These studies indicate an increasing use of individuated information with age, but they also suggest that older children continue to consider intergroup characteristics when forming social judgments about group members. However, previous developmental research on children's judgments of individual social group members has not focused specifically on the linkage between intergroup and intragroup judgments.

One study (Abrams et al., 2003) examined the relationship between intergroup and intragroup evaluations directly. Six- to 7-year-olds and 10- to 11-year-olds evaluated normative and deviant targets from the in-group or out-group summer play scheme. As expected, all ages expressed general intergroup bias. In line with the idea that SGD emerge later than general intergroup bias, the older children differentiated more strongly between the two targets in terms of how acceptable each target would be to other members of each group (a measure we label differential inclusion). Differential inclusion is similar to the concept of perspective taking that has been researched previously in the social (Selman, 1971, 1980) and ethnic domains (Quintana, 1998, 1999). That research shows that from approximately 10 years of age children are able to understand how social groups will view the actions of other individuals. It may follow that older children also become more sensitive to the evaluative implications for other members of the group when a group member undermines group norms (cf. Quintana, 1994, 1998; Ruble et al., in press). In line with this idea, Abrams et al. (2003) found only the older children evaluated the normative in-group and deviant out-group member more positively than the deviant in-group member and normative out-group member. That is, they favored the target from either group who showed relatively greater support for the in-group (differential evaluation measure). Moreover, the effects of age and intergroup bias on differential evaluation were mediated by differential inclusion.

The Abrams et al. (2003) study has several limitations and leaves important questions unanswered. First, Abrams et al. only compared two age groups (6- to 7-year-olds and 10- to 11-year-olds) and for practical reasons had only small numbers of participants $(N=64)$, and one age group was sampled only from one play scheme. The present study includes 476 children whose ages ranged from 5 to more than 11 years and who were drawn randomly from different schools within each condition. This allowed us to investigate evidence for SGD among slightly younger children than before and to use age as a continuous variable. This larger sample and better control allows us to investigate potentially important but small effects, and to examine effects of moderating variables, including identification with the in-group. Second, a methodological limitation in the Abrams et al. study was that the deviant target, but not the normative target, was given a gender-ambiguous name (i.e., Jo). This confound between target gender ambiguity and the normative or deviant factor meant it was possible that evaluation of the deviant target was somehow affected by gender ambiguity. Thus, we removed the confound from the present study by using only male targets.

A central variable in the SGD model is identification with the group. The motivation to upgrade 
individuals who provide validation for in-group norms arises because that group is important to the self-concept. Abrams et al. (2003) aimed only to determine whether there was an age difference in evaluations of deviant group members but did not investigate the role of social identification. Therefore, in the present study, we included measures of children's identification with the in-group. Identification is an important moderating cognitive-motivational variable in the SGD model. Research with adults shows that SGD operate more strongly when group membership is more salient (Marques et al., 1998) and when people identify more with the group (Abrams et al., 2000, Experiment 2; Abrams et al., 2002, Study 1; Coull, Yzerbyt, Castano, Paladino, \& Leemans, 2001; Hutchison \& Abrams, 2003). It seems reasonable to expect that high-identifying children should also be more concerned than low-identifying children to express different evaluations of people who are more and less acceptable to in-group members.

With age, children develop a more sophisticated understanding of how group members' behavior reflects on their own and others' social identity (Quintana, 1994, 1998; Ruble et al., in press). Consequently, we might expect older children to use their identity-based concerns more systematically when making a connection between differential inclusion and differential evaluation. Thus, as children get older we expect the high identifiers' evaluations of group members to be based more strongly on their perceptions of differential inclusion, but low identifiers to be less likely to use that criterion when evaluating group members.

We expected children of all ages to show significant in-group preference on measures of general support for each soccer team (general intergroup bias hypothesis).

The remaining measures focused on intragroup judgments. First, as a manipulation check, we measured children's perceptual accuracy in reporting the behavior of normative and deviant individuals. We also measured how typical they judged normative and deviant targets to be of the member's group. On the basis of previous work, we expected children of all ages to be able to detect that normative and deviant targets differed in typicality.

The general SGD hypothesis is that intergroup and intragroup differentiation should be positively related. Therefore, intergroup bias should be related positively to measures of intragroup differentiation among group members (described later) in terms of their acceptability within the groups and evaluations of the members.
SGD involve a subjective sense of how other group members would feel about deviants within the group context, that is, how the group dynamics might affect the way the group responds to deviant members. To tap this type of understanding, we measured judgments of how acceptable normative and deviant members would be to other members of each group (group inclusion measures). We expected that normative members would be perceived as being more acceptable to their own group than to the opposite group, and more acceptable to their own group than to deviant members. We also expected that deviant members would be perceived as more acceptable to opposing groups than to their own groups.

The SGD model proposes that evaluations of members within either group (target evaluations) will be differentiated such that most positive evaluations will be toward those who provide relatively greater support for in-group norms. We expect that normative in-group members will be favored over deviant in-group members, and deviant out-group members will be favored over normative out-group members. When this effect becomes strong, deviant out-group members will be evaluated more positively than deviant in-group members, similar to the black sheep effect.

Our developmental SGD hypothesis was that older children should differentiate more strongly than younger children on both group inclusion and target evaluations. Specifically, older children should be able to distinguish more clearly between the acceptability of normative and deviant targets to each group (on an overall index of differential inclusion), and they should show stronger differential evaluation between normative and deviant group members (on an overall index of differential evaluation).

Differential evaluations (such as the black sheep effect) that are associated with the operation of SGD should reflect in part an understanding how acceptable a particular behavior is to members of different groups. This understanding should increase with age. We therefore predicted that differential inclusion would mediate the effects of age on differential evaluation (mediation hypothesis). We also considered the possibility that age might augment the effects of differential inclusion on differential evaluation because older children would be better able to understand the implications of differential inclusion for the way group members should be evaluated. This would be reflected in a significant Age $\times$ Differential Inclusion interaction that affects differential evaluations (developmental moderation hypothesis). 
Finally, the SGD model holds that stronger identification with the in-group is associated with increased differential evaluations of among-group members because of heightened desire to sustain ingroup norms (SGD identification hypothesis). It also follows that the effect of differential inclusion on differential evaluation will also be larger among people who identify more strongly (identity moderation hypothesis). Given our expectations that age and social identification could increase the effect of differential inclusion on differential evaluation for different reasons, we also predicted a significant three-way interaction such that support for the identity moderation hypothesis should be manifested more strongly among older children (developmental identity moderation hypothesis).

\section{Method}

A preliminary study was conducted 8 weeks before the start of the June 2002 World Cup Soccer Finals in Japan and South Korea. The main study was conducted 4 weeks later during a 2-week period in May 2002.

\section{Preliminary Study of Normative Expectations}

Design and method. The preliminary study was conducted to ensure that children could distinguish between the typicality of statements designed to be normative and deviant in the main study. We also wanted to ensure that these statements would be viewed as normative or deviant regardless of whether they were made by in-group and out-group members. The design of the main study required it to be clear that even the deviant target was a supporter of his or her own team. For this reason, the deviant group member (target) would make one normative statement and one deviant statement. We also decided the main study should include two statements for each target, to ensure the amount of content was equivalent for the two targets. Therefore, in the preliminary study, we aimed to find three equally normative statements (two to be made by normative targets and one to be made by deviant targets) and one statement that would be considered deviant (to be made by deviant targets).

Twenty-seven male children (fifteen 6- to 7-yearolds and twelve 10- to 11-year-olds) from a school in the southeast of England were tested individually by a female experimenter. Children were asked to estimate the proportion of England and Germany soccer supporters who would agree with a series of statements. First, the response format was explained.
A picture of 12 stick people was presented and described as a group of children. Then, it was explained how to answer the question, "How many of these children do you think would say 'I love eating sweets'?" A series of response scales was presented, showing proportionate numbers of stick people with labels representing all the children, most of the children, about half of the children, a few of the children, and none of the children. This was later scored as a scale from 1 (none) to 5 (all). Once the child's responses indicated that he or she understood how to use the response format, the main questionnaire was presented.

Children were asked to, "Think about England soccer supporters. Here is a group of 15 supporters of the England soccer team talking about the England soccer team and the World Cup. This group of England soccer fans was asked to imagine that England have to play Germany in the World Cup final this summer. Think about what the fans might say about the England soccer team. How many of the England soccer supporters in this group would say each of these statements?" There followed a series of normative and deviant statements for potential inclusion in the main study. For economy of space we report analyses only for the items that were retained for use in the main study. The normative statements were positive statements about the team. In the main study in the in-group condition, two of these were attributed to the normative target: "I think England is the best team" and "Even if we lost the game to Germany I'd still say that England are the better team." Another was attributed to the deviant target, "It's great when England play well. They are a fantastic team." The deviant target also uttered a deviant statement, "When Germany play well, I always clap and cheer" (when targets were German the referent in-group was Germany rather than England).

Results. The average of the two normative target statements were judged to be equally typical when attributed to in-group targets $(M=4.61, S D=.51)$ and out-group targets $(M=4.40, S D=0.74)$, $t(24)=1.04, p<.31$. The single normative statement attributed to deviant in-group $(M=4.74, S D=0.66)$ and out-group target $(M=4.60, S D=0.91)$ was also equivalent, $t(24)=0.35, p<.73$. Comparison of the average of the two normative statements attributed to the normative target and the single normative statement attributed to the deviant target in the main study revealed that they were judged to be equally typical, both when uttered by in-group targets, $t(26)=1.02, \quad p<.32$, and by out-group targets, $t(24)=1.73, p<.10$. 
Next, we checked that the deviant statements were judged to be less typical than the normative statements. This was confirmed both when the statements were attributed to the in-group targets $(M=2.59, S D=1.31$ and $M=4.74, S D=0.66$, respectively), $t(26)=7.94, p<001$, and to the out-group targets $(M=2.88, S D=1.42$ and $M=4.64, S D=0.91$, respectively), $t(24)=5.06, p<.001$. The pairs of statements made by in-group and out-group deviant targets were judged as similarly atypical, $t(24)=0.30, p=0.77$. Finally, the mean typicality of the two statements to be made by normative targets was significantly greater the mean typicality of two the statements uttered by deviant targets, either when the statements were attributed to in-group targets, $t(26)=6.43, p<.001$, or to out-group targets, $t(24)=2.92, p<.007$. Based on these data we felt confident that the normative and deviant statements differed in terms of their perceived typicality, and that the degree of typicality of each type of statement did not vary as a function of the group membership of the speaker. These results confirmed that both younger and older children expected that soccer fans will normally only express attitudes that support fans' own team. Expressing a positive evaluation of the opposing team is judged to be deviant.

Finally, we checked for age differences in judgments of typicality and found that older children rated normative statements to be more typical $(M=4.73, S D=0.39)$ than did younger children $(M=4.37, S D=0.47), F(1,23)=7.86, p<.01$. However, age did not interact with any of the differences between typicality ratings mentioned earlier, all $F \mathrm{~s}<1.07$, all $p \mathrm{~s}>.30$. Therefore, we decided to use these statements as stimuli in the main study.

\section{Main Study Design and Participants}

Age was a continuous independent variable $(M=104.63$ months, $S D=21.91$; range $=62$ months to 143 months), crossed with a between-participants variable (group: in-group vs. out-group) and a within-participants variable (target: normative vs. deviant).

Participants were 519 children, and data were treated as valid for 476. A criterion for participation was that the child was self-defined as English. The children were predominantly of Caucasian origin $(86 \%)$, and all were English by nationality. Assignment to condition was random within each school. Forty seven percent of the participants were female, and gender was evenly distributed between conditions, $\chi^{2}(1)=0.32, p=.57$.
Procedure. All children participated individually under the supervision of a female experimenter. The experimenter interviewed the younger children with the questionnaire in front of them. The older children, given their more advanced reading ability, were allowed to self-complete the questionnaire in the presence of the experimenter who sat directly next to each child. The experimenter monitored all children's progress through each question ensuring and checking with them whether they understood the questions. This procedure was used to ensure that the accountability cues were similar for children in all age groups because previous research with adults suggested that variations in accountability (to other group members) may increase SGD effects (Marques et al., 1998).

Stimulus materials and measures. The first page of the questionnaire was used to introduce the study and to ensure that children understood how to use the response scales. It included a series of statements about the weather that day, accompanied by an explanation of which face to tick to describe it. A circular feeling face was used to represent each point on the 5-point scale. The scale had the mouth in a downward position (1) through horizontal (3) to a large smile position (5). After the child had correctly identified the relevant response for each type of weather the experimenter proceeded with the experiment.

The questionnaire had two sections: team identification, and intergroup and target judgments. The sequence of the sections was counterbalanced. The team identification measures determined children's identification with the England soccer team. Responses were made on the feeling faces scale anchored with not at all (1) and very much (5). There were four items: "How much do you like the England soccer team?" "Do you like it when England win soccer matches?" "Do you like to watch England games on TV?" "Do you cheer for England in soccer?"

The intergroup and target judgments section of the questionnaire began with two items to measure general intergroup bias: "How do you feel about supporting the England soccer team?" "How do you feel about supporting the German soccer team?"

Next, children were presented with statements made by two male target characters, Alex and Mark, who were introduced as real fans of either the England or German soccer team, who had supported their teams since they were children and went to all the games and watched them on TV. In the in-group condition Alex and Mark were described as England soccer supporters and in the out-group condition 
they were described as German soccer supporters. Children were told that "Alex and Mark were asked to imagine that England have to play Germany in the World Cup final next month. Here are some of the things Alex and Mark said." Across conditions, Alex was presented as a normative target and Mark was presented as a deviant target. The statements made by the normative and deviant targets are described in our preliminary study of normative expectations.

There followed a series of nine questions about Alex and Mark. These were designed to assess whether children correctly perceived that the deviant was deviant, how typical the targets were of their groups, how likely they were to be accepted by other members of each group, and how the child evaluated the target. The order in which targets were judged was counterbalanced so that half the children judged the normative target first, and the rest judged the deviant target first. Before answering the questions, children were reminded of what the target had said.

The first two questions provided a perceptual accuracy check to see whether children understood which preferences the member had expressed: "What does [target] feel about being an [in-group team] supporter?" "What do you think [target] would feel about being an [out-group team] supporter instead?" The next item tapped target typicality to check that the normative targets were viewed as more typical (i.e., normative) of their groups than were the deviant targets. The item asked, "How many other [same team] supporters would think the same as [target]?" The response options (scored from 1 to 5) were: none, hardly any, quite a few, a lot, and almost all. Above each label was a schematic picture that depicted $0,4,10,18$, or 40 people, respectively.

Two questions used the face scales to measure perceived same-group inclusion and other-group inclusion. These were designed to reveal whether children understood the implications of the targets' attitudes for the acceptability of the target to members of each group. The questions were: "How do you think other [same team] supporters would feel towards [target]?" "How do you think [opposing team] supporters would feel toward [target]?"

Four items tapped target evaluations. These asked, "How do you feel towards [target]?" "How do you feel about what [target] said?" "How much would you like to be [target's] friend?" "In a game, how much would you want [target] to be on your team?" Responses were made using the feeling face scales.

\section{Results}

We first analyzed the data to investigate possible effects of school and gender. Previous research has revealed pronounced in-group gender bias among children (e.g., Bigler, 1995; Martin, 1989; Powlishta, 1995; Yee \& Brown, 1994). Gender is not strictly relevant to the present hypotheses, or to the comparison between the soccer teams, and we had no a priori reason to expect gender to affect responses (cf. Abrams et al., 2003). To minimize the complexity of the design, we had elected to use only male targets and to check if gender bias was manifested. This could happen if male participants favored all targets more than female participants or if males would differentiate more between normative and deviant targets than females. In fact, there were no significant multivariate main effects or interactions involving either gender or school, $F s<1.17, p s>.20$. Therefore, these variables were not included in the analyses reported.

To ascertain whether the basic pattern of findings fits the SGD model, we conducted mixed analyses of variance (ANOVAs) with target (normative vs. deviant) as a within-participants variable and group (in-group vs. out-group) as a between-participants variable. The means for simple measures of typicality, inclusion, and evaluation as a function of group and target type are shown in Table 1, and correlations among variables within levels of group are presented for information in Table 2. Our developmental and identity hypotheses were tested using multiple regression analyses with age (in months) or identification as continuous independent

Table 1

Means (Standard Deviations) for Measures of Typicality, Group Inclusion, and Evaluation as a Function of Group Membership and Target Type

\begin{tabular}{|c|c|c|c|c|}
\hline \multirow{2}{*}{$\begin{array}{l}\text { Group } \\
\text { Target }\end{array}$} & \multicolumn{2}{|c|}{ In-group } & \multicolumn{2}{|c|}{ Out-group } \\
\hline & Normative & Deviant & Normative & Deviant \\
\hline Typicality & $\begin{array}{r}4.60_{\mathrm{a}} \\
(0.67)\end{array}$ & $\begin{array}{c}2.64 \\
(1.29)\end{array}$ & $\begin{array}{r}4.31_{\mathrm{a}} \\
(0.97)\end{array}$ & $\begin{array}{c}3.00 \\
(1.22)\end{array}$ \\
\hline $\begin{array}{l}\text { Inclusion by } \\
\text { target's group }\end{array}$ & $\begin{array}{r}4.60_{\mathrm{b}} \\
(0.79)\end{array}$ & $\begin{array}{r}2.65_{\mathrm{c}} \\
(1.43)\end{array}$ & $\begin{array}{r}4.43_{\mathrm{b}} \\
(1.04)\end{array}$ & $\begin{array}{r}2.92_{\mathrm{c}} \\
(1.39)\end{array}$ \\
\hline $\begin{array}{l}\text { Inclusion by } \\
\text { other group }\end{array}$ & $\begin{array}{r}1.72 * \\
(1.21)\end{array}$ & $\begin{array}{r}4.20_{c} \\
(1.08)\end{array}$ & $\begin{array}{l}1.70_{*} \\
(1.15)\end{array}$ & $\begin{array}{r}3.87_{c} \\
(1.22)\end{array}$ \\
\hline Evaluation & $\begin{array}{c}4.35 \\
(0.72)\end{array}$ & $\begin{array}{c}3.08 \\
(1.29)\end{array}$ & $\begin{array}{c}2.49 \\
(1.23)\end{array}$ & $\begin{array}{c}3.69 \\
(1.05)\end{array}$ \\
\hline
\end{tabular}

Note. Scores on each variable may range from 1 to 5 . Within rows all means differ significantly $(p<.001)$ with the exception of those sharing subscripts a $(p<.01)$, b or c $(p<.05)$, or * (ns). For each target, inclusion by target's group differs significantly from inclusion by other group $(p<.001)$. 
Table 2

Zero-Order Correlations Among Variables Within In-Group and Out-Group Conditions

\begin{tabular}{|c|c|c|c|c|c|c|c|c|c|}
\hline & 1 & 2 & 3 & 4 & 5 & 6 & 7 & 8 & 9 \\
\hline 1. Age & - & .00 & $.23^{* * *}$ & .07 & $-.22 * * *$ & $-.30^{* * *}$ & $.16^{* *}$ & $-.24^{* * *}$ & $-.37^{* * *}$ \\
\hline 2. Identification & -.05 & - & $.51^{* * *}$ & .06 & -.04 & $.14^{*}$ & .07 & $.33^{* * *}$ & .06 \\
\hline 3. Intergroup bias & $.18^{* *}$ & $.59^{* * *}$ & - & $.15^{*}$ & $-.14^{*}$ & -.11 & .12 & $.26^{* * *}$ & $-.23 * * *$ \\
\hline 4. Normative target same-group inclusion & .12 & .04 & $.14^{*}$ & - & $-.21^{* * *}$ & -.08 & .03 & $.24^{* * *}$ & -.05 \\
\hline 5. Normative target opposite-group inclusion & $-.22 * * *$ & .00 & $-.19^{* *}$ & -.08 & - & $.21^{* * *}$ & -.09 & $-.14^{*}$ & $.19^{* *}$ \\
\hline 6. Deviant target same-group inclusion & $-.23 * * *$ & -.03 & -.09 & -.06 & $.21^{* *}$ & - & $-.30 * * *$ & .09 & $.61^{* * *}$ \\
\hline 7. Deviant target opposite-group inclusion & .03 & $.13^{*}$ & $.21^{* *}$ & $.25^{* * *}$ & -.03 & -.03 & - & -.07 & $-.18^{* *}$ \\
\hline 8. Evaluation of normative & $-.22 * * *$ & $-.24^{* * *}$ & $-.40^{* * *}$ & -.03 & $.32^{* * *}$ & $.18^{* *}$ & .00 & - & .03 \\
\hline 9. Evaluation of deviant & -.08 & $.27^{* * *}$ & $.13^{*}$ & .06 & -.03 & .08 & $.45^{* * *}$ & -.09 & - \\
\hline
\end{tabular}

Note. In-group and out-group condition correlations are above and below the diagonal, respectively. Intergroup bias is the difference between general in-group evaluation and general out-group evaluation.

${ }^{*} p<.05 .{ }^{* *} p<.01 .{ }^{*}{ }^{* *} p<.001$.

Table 3

Summary of Computation and Interpretation of Differentiation Scores

\begin{tabular}{|c|c|c|}
\hline Variable & Computation and constituent variables & Interpretation \\
\hline General intergroup bias & Support for England minus support for Germany. & Higher score $=$ more bias in favor of England . \\
\hline Group inclusion & $\begin{array}{l}\text { Rating of target's acceptability to target's group } \\
\text { minus rating of target's acceptability to } \\
\text { opposing group. }\end{array}$ & $\begin{array}{l}\text { More positive score }=\text { more inclusion in same } \\
\text { group relative to opposing group. }\end{array}$ \\
\hline Differential inclusion & $\begin{array}{l}\text { Group-inclusion score for normative target minus } \\
\text { group-inclusion score for deviant target. }\end{array}$ & $\begin{array}{l}\text { Higher score }=\text { judging larger differences in the } \\
\text { acceptability of normative and deviant mem- } \\
\text { bers to same and opposing groups. }\end{array}$ \\
\hline Target bias & $\begin{array}{l}\text { Evaluation of normative target minus evaluation of } \\
\text { deviant target. }\end{array}$ & $\begin{array}{l}\text { Positive score }=\text { normative target is favored; } \\
\text { negative score }=\text { deviant target is favored. }\end{array}$ \\
\hline Differential evaluation & $\begin{array}{l}\text { In the in-group condition the score is derived from } \\
\text { evaluation of normative target minus } \\
\text { evaluation of deviant target. In the out-group } \\
\text { condition the score is derived from evaluation } \\
\text { of deviant target minus normative target. }\end{array}$ & $\begin{array}{l}\text { Across the in-group and out-group conditions, } \\
\text { positive score = greater favorability toward } \\
\text { target that shows most support for the in } \\
\text { group. }\end{array}$ \\
\hline
\end{tabular}

variables. We were primarily interested in differences in judgments of normative and deviant targets; therefore, these analyses focus on the magnitude of these differences (cf. Judd, Kenny, \& McClelland, 2001). A summary of the way these difference scores were derived is provided in Table 3. We also conducted regression analyses of judgments of each target separately. These analyses are not reported here for reasons of space and clarity, and because they do not substantively alter the findings or conclusions. Details of these analyses are available from the first author.

\section{Manipulation Checks}

Perceptual accuracy. Data from 8 children were excluded because it was evident during testing that they were not paying attention to the task. We screened the perceptual accuracy measure data from the remaining children and excluded $35(7 \%)$ participants who had inaccurately judged the deviant targets to be more favorable to the target's group than the normative target was (although all significant effects were unaffected by this). Younger children were slightly more likely to have failed the manipulation check, $r(519)=-.15, p<.001$. Data for the remaining 476 children were used for subsequent analyses. The initial and final numbers included for analysis reflected the availability of children at the time of the study. When classified in 12-month age bands, the initial (final) numbers were 38 (31) aged 5, 75 (59) aged 6, 88 (83) aged 7, 76 (72) aged 8, 80 (79) aged 9, 85 (80) aged 10, and 77 (72) aged 11. Random assignment to condition was 
successful within all age levels, maximum difference between cell sizes in the in-group and out-group condition $=4$, modal difference $=1, \chi^{2}(6)=0.32$, $p=.99$.

Order effects. We examined all the main dependent variables described next to see whether there were any effects of order of presentation of the team identification section, and order of presentation of the normative and deviant targets. Across all the measures none of the differences was significant, smallest $t(474)=0.54, p<.39$, largest $t(474)=1.77$, $p=.077$. Therefore, we collapsed across these factors for subsequent analyses.

\section{General Intergroup Bias}

The two measures of support for the in-group and out-group teams were answered before children received information about the target individuals. Consistent with the general intergroup bias hypothesis, children supported England $(M=4.31$, $S D=1.17)$ significantly more than Germany $(M=$ $1.88, S D=1.30), t(473)=38.5, p<.001$.

We computed a measure of general intergroup bias by subtracting support for the out-group from support for the in-group. Regression analysis revealed a highly significant effect of age, $\beta=0.20$, $t(471)=4.45, p<.001$. Children expressed stronger intergroup bias with age. As expected, there was no effect of group on intergroup bias, $\beta=.03, t(471)=$ 0.70 , and no interaction between age and group, $\beta=-0.16, t(471)=0.37$. When we examined bias within each 12-month age category we found it to be significantly different from zero in all ages (all ps $<.05)$.

\section{Target Typicality}

Normative targets were viewed as more typical $(M=4.46)$ than deviant targets $(M=2.82), F(1$, $459)=432.7, p<.001$. The normative target was rated significantly lower in the in-group condition than in the out-group condition, $\beta=0.20, t(471)=3.66$, $p<.001$. Ratings of deviant typicality were lower in the in-group condition, $\beta=0.14, t(471)=3.12, p<.01$, and reduced significantly with age, $\beta=-.22$, $t(471)=4.89, p<.001$. We computed a score to reflect the difference in perceived typicality of the two targets (normative minus deviant). The regression analysis revealed significant effects of group, $\beta=-$ $.20, t=4.50, p<.001$, and age, $\beta=0.17, t=3.79$, $p<.001$, but no interaction between them, $\beta=.08$, $t=1.72, p=.09$. Normative and deviant in-group targets were judged to differ more in typicality than normative and deviant out-group targets regardless of children's age. Children also distinguished the typicality of normative and deviant targets more as they got older.

\section{Group Inclusion}

The measures of group inclusion were intended to capture children's interpretation of the meaning of deviance for dynamics within the target's group. Same-group inclusion was perceived to be higher for the normative than deviant target, whereas opposite-group inclusion was perceived to be lower for the normative than deviant target, $F(1$, $460)=389.9, p<.001 ; F(1,460)=768.5, p<.001$, respectively. We reduced the measures of group inclusion for the two targets to a single index. For each target we subtracted the other-group inclusion rating from the same-group inclusion rating (the score would typically be positive for a normative target and negative for a deviant target). We then subtracted the score for the deviant from the score for the normative target. This provided an overall measure of differential inclusion. The higher the score, the more the children expected normative targets to be accepted by the target's group and rejected by the opposing group, and the more they expected deviant targets to accepted by the opposing group but rejected by the target's group.

Regression analysis on this score revealed a significant effect of group, $\beta=-.15, t=3.46, p<.001$, and a significant effect of age, $\beta=.20, t(473)=4.56$, $p<.001$, but no interaction between them, $\hat{a}=-.02$, $t=0.54$. Thus, children expected in-group members to distinguish more strongly than out-group members between the acceptability of normative and deviant targets. With increasing age children developed stronger expectations that normative members would be accepted and deviant targets rejected by their respective groups relative to their treatment by opposing groups (see also Table 2). This is consistent with our developmental SGD hypothesis that older children would be more sensitive to the intergroup implications of deviance.

\section{Target Evaluations}

The four items used to evaluate normative members and the four used to evaluate deviant members were factor analyzed. This revealed two distinct factors, eigenvalues $=3.54$ and 2.42 , accounting for $44.2 \%$ and $30.2 \%$ of the variance, respectively. The significant items in each factor correspond to the two different targets. We therefore averaged the 
responses to the four items for each target to produce measures of normative target evaluation and deviant target evaluation (Cronbach's alpha $=$ 0.90 and 0.86 , respectively). The ANOVA revealed no significant effect of target, $F(1,474)=0.24$, but highly significant effects of group, $F(1,474)=81.03$, $p<.001$, and Group $\times$ Target interaction, $F(1,474)=$ $292.74, p<.001$.

Simple effects analyses revealed that within the in-group condition the normative target $(M=4.35$, $S D=0.72)$ was favored over the deviant target, $(M=3.08, \quad S D=1.29), \quad F(1,474)=156.85, p<.001$. Within the out-group condition the reverse was true $(M=2.49, S D=1.23$ and $M=3.69, S D=1.05$, respectively), $F(1,474)=136.39, p<.001$. Moreover, the in-group normative target was favored over the outgroup normative target, $F(1,474)=408.16, p<.001$, whereas the out-group deviant was favored over the in-group deviant, $F(1,474)=32.01, p<.001$, consistent with the operation of SGD and a pattern comparable to the black sheep effect.

Next, we subtracted the rating of the deviant target from the rating of the normative target (target bias). A positive target bias score represents preference of the normative over the deviant target, and a negative score represents preference of the deviant over the normative target. We used multiple regression to analyze the effects of group and age on this measure. There was a significant effect of group, corresponding to the Group $\times$ Target interaction on target evaluations reported earlier, $\beta=-.62, t(470)=$ $17.02, p<.001$. There was no significant effect of age, $\beta=.03$, but there was a significant Age $\times$ Group interaction, $\beta=-.12, t(470)=3.39, p<.001$, indicating that the effect of group increases with age. Figure 1 illustrates this interaction by plotting the slopes for children $1 S D$ below and above the mean age for the sample, derived from the regression equation. Compared with younger children, older children show a relatively stronger target bias in favor of the in-group normative versus the in-group deviant target, and in favor of the out-group deviant versus the out-group normative target. This is in line with the developmental SGD hypothesis.

\section{Intergroup and Intragroup Differentiation}

The general SGD hypothesis is that differentiation among group members occurs in concert with general intergroup bias. The previous analyses demonstrated that general intergroup bias, differential inclusion, and target bias in support of the ingroup all increase with age. To test the general SGD hypothesis we used differential inclusion as a

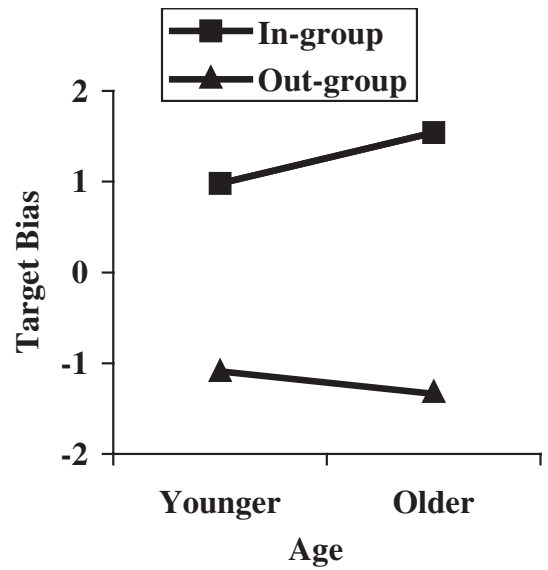

Fig. 1. Evaluation of normative group members minus evaluation of deviant group members (target bias) in the in-group condition and out-group condition, as a function of age. Values of target bias are derived from a regression equation in which target bias is the dependent variable and age, group (in-group vs. out-group), and their interaction, are independent variables. Effects of age are represented by values $\pm 1 S D$ from the mean age.

dependent measure and general intergroup bias and age as predictors in a regression analysis. Consistent with the hypothesis, independent of the significant effects of age, $\beta=.18, t(471)=3.89$, $p<.001$, there was a significant effect of intergroup bias, $\beta=.13, t=2.76, p<.006$. The Age $\times$ Bias interaction was not significant, $\beta=-.05, t=.99$. To conduct a comparable analysis for target bias that could be used with the same conceptual status across the in-group and out-group conditions, we followed previous research (Abrams et al., 2002; Abrams et al., 2003) to derive an index of differential evaluation. Specifically, we used the target bias score in the in-group condition (evaluation of normative minus evaluation of deviant) and the reversed target bias score in the out-group condition (evaluation of the deviant target minus evaluation of the normative target). Higher differential evaluation scores represent a stronger preference for the target that provides most support for the ingroup.

When we used differential evaluation as the dependent variable the pattern was similar to that for differential inclusion. Independent of the significant effect of age, $\beta=.15, t(471)=3.33, p<.001$, there was a significant effect of general intergroup bias, $\beta=.34, t=7.65, p<.001$, but no significant interaction, $\beta=.07, t=1.47, p<.14$. Thus, for both differential inclusion and differential evaluation, children who expressed more intergroup bias also expressed greater differentiation between targets, in line with the general SGD hypothesis. 


\section{Mediation and Developmental Moderation}

Our mediation hypothesis was that the effect of age on differential evaluation should be mediated by differential inclusiveness. To test this hypothesis we used differential evaluation as a dependent variable and then entered differential inclusiveness before testing the remaining variance attributable to age and intergroup bias. The relationship between differential evaluation and differential inclusiveness was significant, $\beta=.35, t(471)=8.11, p<.001$. Moreover, the effect of age on differential evaluation was nonsignificant once differential inclusiveness was included in the regression, $\beta=.03, t=.75, p<.45$, and the effect of intergroup bias remained significant, $\beta=.30, t=7.08, p<.001$.

A formal test of the significance of mediation is provided by the Goodman (I) version of the Sobel test (Goodman, 1960), as specified in Baron and Kenny (1986; see also MacKinnon, Warsi, \& Dwyer, 1995). This showed that the effect of intergroup bias on differential evaluation is partly, and significantly, mediated by differential inclusion, $Z=2.76, p<.01$. Moreover, the effect of age on differential evaluation is entirely and significantly mediated by differential inclusion, $Z=3.41, p<.001$, as predicted by our developmental model. At the suggestion of a reviewer, we also checked for reverse mediation, that is, that the effects of age on differential inclusion may be mediated by differential evaluation. When differential evaluation was included as a mediator, the effect of age on differential inclusion remained significant, $\beta=.15, t=3.44, p<.001$. The Sobel test revealed only marginally significant evidence of partial mediation by differential evaluation, $Z=1.92$, $p=.054$. In summary, the age-related increase in differential evaluation depends on age-related increases in differential inclusion.

Finally, we investigated whether age and differential inclusiveness interacted to predict differential evaluation. Consistent with the developmental moderation hypothesis, the Age $\times$ Differential Inclusiveness interaction was significant, $\beta=-.09, t=2.11$, $p<.035$, showing that the impact of differential inclusiveness on differential evaluation increased with age.

These analyses are consistent with the following conclusions. Age affects intergroup bias, and both variables affect differential inclusion. Intergroup bias and differential inclusion both affect differential evaluation. Finally, the impact of differential inclusiveness on differential evaluation increases slightly with age. These findings are summarized in the path model in Figure 2, and zero-order correlations among variables are shown in Table 2 .

\section{Group Identification}

The four team-identification items were averaged to form a measure of group identification. This was reliable (Cronbach's alpha $=0.80$ ). Levels of identification did not differ as a function of group, $F(1$, $474)=.08$. To test the SGD identification hypothesis, we used multiple regression to examine whether age, identification, and their interaction affected intergroup bias, differential inclusion, and differential evaluation. For intergroup bias there were highly significant effects of age, $\beta=.21, t=5.77, p<.001$, and identification, $\beta=.56, t=15.98, p<.001$, but no interaction between these variables, $\beta=.01, t=0.39$. For differential inclusion there was only a significant effect of age, $\beta=.20, t=4.50, p<.001$, and no effect of identification or interaction between these variables, $\beta \mathrm{s}=.02$ and -.02 , ts $=.40$ and .38 , respectively. For differential evaluation there was a significant effect of both age, $\beta=.16, t=3.56, p<.001$, and identification, $\beta=.24, t=5.44, \quad p<.001$, but no significant interaction, $\beta=.05, t=1.03, p<.30$. Therefore, independent of the effects of age de-

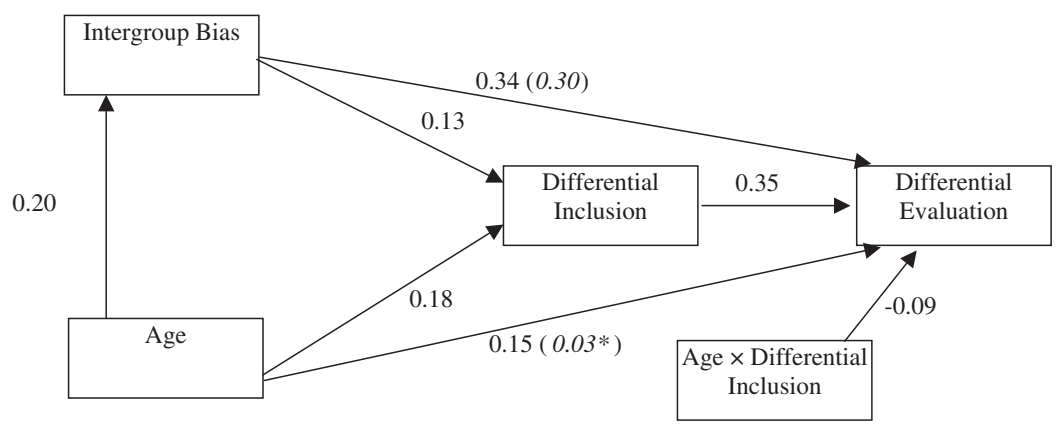

Fig. 2. Path diagram of the effects of intergroup bias and age on differential inclusion and differential evaluation. Path weights are standardized regression coefficients. Italicized coefficients are the effects when differential inclusion is partialed out. All paths are significant except $* p>.05$. 
scribed earlier and consistent with the hypothesis, identification significantly affected intergroup bias and differential evaluation. However, identification did not affect differential inclusion.

\section{Identity Moderation Analyses}

From SIT and research on SGD in adults, we hypothesized that the impact of differential inclusiveness on differential evaluation should be moderated by the strength of identification with the ingroup (identity moderation hypothesis). Therefore, we conducted a regression analysis using differential evaluation as the dependent variable, and identification, differential inclusion, and their interaction as predictor variables. There were significant effects of differential inclusion, $\beta=.34, t=8.24, p<.001$, and identification, $\beta=.23, t=5.55, p<.001$. Increases in differential inclusion and identification both related to increased differential evaluation. Moreover, the interaction between these variables was significant, $\beta=.10, t=2.31, p<.021$. We examined the simple regression slopes of differential inclusion on evaluative differentiation within high identifiers and low identifiers (defined by scores $1 S D$ above and below the mean identification score), following the procedures outlined by Aiken and West (1991). In line with the identity moderation hypothesis, the relationship was larger among high identifiers, $\beta=.45$, $t=7.71, p<.001$, than among low identifiers, $\beta=.24$, $t=4.22, p<.001$.

The developmental identity moderation hypothesis was that as children get older the moderating effect of identification on the relationship between differential inclusion and differential evaluation should increase. Consistent with this expectation, when age was included in the regression analysis, the main effect of differential inclusion, $\beta=.33$, $t=7.80, p<.001$, and the Differential Inclusion $\times$ Age interaction, $\beta=-.09, t=2.14, p<.04$, remained significant. The effects of identification, $\beta=.19$, $t=4.39, p<.001$, and the Identification $\times$ Differential Inclusion interaction remained significant, $\beta=.09$, $t=2.06, p<.04$. Moreover, the Age $\times$ Identification $\times$ Differential Inclusion interaction was also significant, $\beta=.11, t=2.53, p<.012$. We decomposed the significant three-way interaction to examine the simple two-way interactions within levels of age, using values $\pm 1 S D$ above and below the mean. The Differential Inclusion $\times$ Identification interaction was significant among older children, $\beta=.22, t=3.43$, $p<.001$, but not among younger children, $\beta=-.04$, $t=0.57$. Further analysis of the simple effect of differential inclusion on differential evaluation within high and low identifiers among older children revealed that differential inclusion was significantly related to differential evaluation among high identifiers, $\beta=.44, t=5.40, p<.001$, but not among low identifiers, $\beta=.03, t=0.36$. The pattern is consistent with the developmental identity moderation hypothesis. Whereas identification does not affect the relationship between differential inclusion and differential evaluation among younger children, it has a significant impact among older children. Only among those who identify highly with the group does a perception of differential inclusion relate to their own evaluations of normative and deviant group members. The pattern for this interaction is

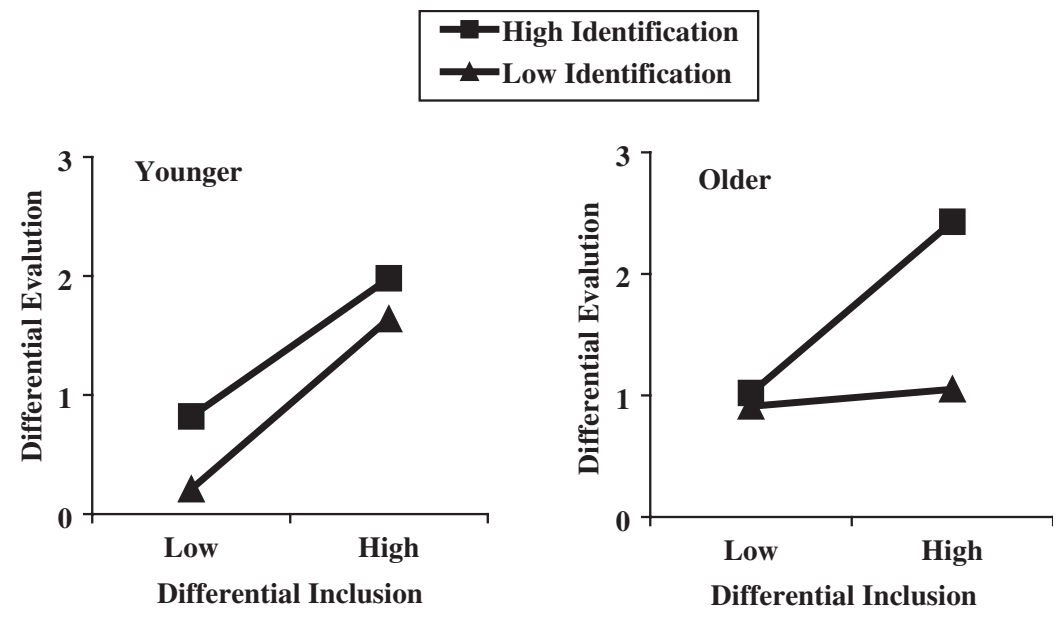

Fig. 3. Effects of age, differential inclusion, and social identity on differential evaluation. Values for differential evaluation are derived from the regression analysis within which identification, differential inclusion, age, and their two-way and three-way interactions were used as predictors. In the figures, to represent younger and older age groups, higher and lower identifiers, and high- and low-differential inclusion, we substituted values $1 S D$ above and below the means for those variables. 
displayed in Figure 3, which presents the separate figures for older and younger age groups, and depicts predicted levels of differential evaluation when identification and differential inclusion are $\pm 1 S D$ from the mean.

\section{Discussion}

Several findings emerge from this study to show that, as children get older, their judgments of deviants reflect their increasing understanding of the relationship between the individual's behavior and their group membership. We discuss each finding separately and then consider the relationship among them.

\section{Intergroup Bias}

Children of all ages showed significant bias in favor of the English soccer team versus the German soccer team. This effect was also significantly stronger as a function of age, consistent with our general intergroup bias hypothesis.

\section{Perceptions of Target Typicality}

The perceptual accuracy check showed that $93 \%$ of children correctly understood that normative targets were more favorable than deviants to the target's team. Moreover, the typicality measure showed that children in all age groups recognized that deviant targets were less typical than normative targets. As expected, this suggests that children as young as 5 years of age are familiar with the idea of loyalty norms, at least in the area of sports team support. This is consistent with theorizing that loyalty norms are basic and pervasive in society, perhaps for evolutionary as well as social reasons (cf. Kurzban \& Leary, 2001; Zdaniuk \& Levine, 2001). The preliminary study and main study both showed that children distinguished the typicality of normative and deviant targets more as they got older.

\section{Differential Inclusion}

In line with our developmental SGD hypothesis, older children were more sensitive to the grouprelated implications of deviance. As predicted, when asked to rate how acceptable the normative and deviant targets would be from the perspective of other members of each group (differential inclusion), differentiation between these targets was significantly greater among older children. This is important for our developmental SGD model because understanding of the intergroup and intragroup implications of deviance is assumed to be a precursor to identity-serving evaluations of group members.

\section{Target Evaluation}

The classic finding in SGD research is that in an intergroup context in which deviants imply support for opposing group norms, normative in-group members are preferred over deviant in-group members, whereas deviant out-group members are preferred over normative out-group members. The so-called black sheep effect (Marques et al., 1988) occurs when deviant out-group members are evaluated more highly than similar deviant in-group members. The results for target evaluations showed that both of these patterns were obtained in the present study. These findings verify a similar but marginally significant pattern in our previous study (Abrams et al., 2003).

Cognitive-developmental theory holds that older children should engage in more individuated judgments and therefore could be expected to base evaluations less on the group membership of the targets. Thus, we might have expected older children to evaluate in-group and out-group deviant targets more similarly to one another because both targets expressed positive sentiments toward both teams. Conversely, evaluations of normative targets would become more divergent with age because normative targets favored different teams. This did not occur. Instead, consistent with our developmental SGD hypothesis, in-group-serving differential evaluation among targets increased with age.

\section{The Relationship Among General Intergroup Bias, Intragroup Differentiation, and Age}

In line with the general SGD hypothesis, general intergroup bias and differential evaluation were positively related, and this finding is the background against which age differences emerged. In particular, our mediation hypothesis was that age differences in evaluative biases toward individual targets would be dependent on children's comprehension of how the social group would perceive the normative and deviant targets (i.e., differential inclusion). Consistent with this idea we found that, independent of the relationship between age and intergroup bias, both age and intergroup bias were associated with a stronger awareness of differential inclusion. As predicted by our developmental moderation hypoth- 
esis, the effect of age on differential evaluation was fully mediated by (and augmented the effects of) differential inclusion. Moreover, there was little evidence that differential evaluation mediated effects of age on differential inclusion. This suggests that age-related effects on differential evaluation reflect children's developing social-cognitive capacity to make sense of normative and deviant behavior in an intergroup context. In contrast, the effects of intergroup bias on differential evaluation were only partially mediated by differential inclusion.

\section{Group Identification}

The SGD model holds that evaluations of groups and their members serve an identity-maintenance function. As expected, we found that identification was strongly related to intergroup bias, independent of age-related changes. In line with our SGD identification hypothesis, identification also affected differential evaluation. It is interesting that identification had no effect on differential inclusion. Thus, identification affected only the measures that related theoretically to positive social identity. Although it is always difficult to separate cognitive and motivational processes, this pattern of findings suggests that the measure of differential inclusion may tap a relatively cognitive process that is independent of identity-relevant goals, whereas the measure of differential evaluation may tap relatively more identity-serving processes.

Based on the SGD model, we predicted that that those who identify more strongly should be more motivated to express evaluative biases to the extent that they perceive targets to be deviant in an intergroup context. This identity moderation hypothesis was upheld. The relationship between differential inclusion and differential evaluation was stronger among children who identified more with their group (see also Abrams et al., 2000; Abrams et al., 2002). Finally, consistent with our developmental identity moderation hypothesis, this interaction effect was strongest among the oldest children. Among older children, only when identity concerns are strong are perceptions of differential inclusion related to differential evaluations. Lower identifiers engage in less evaluative differentiation between normative and deviant members, and they do not relate their evaluations to perceptions of group inclusion. Thus, the present findings show that, for the groups used in this research, older children's evaluations of group members are related to perceptions of differential inclusion more system- atically as their own level of identification with the group increases.

\section{Limitations}

There exist some limitations in the present research. For example, we deliberately used only male targets. We employed an intergroup context that was highly competitive and salient - an international sports competition. This could be viewed as a male-relevant intergroup situation with strong norms. It turned out that there were no sex differences in evaluations of these targets, but it remains conceivable that girls and boys might react differently to female targets in the same situation.

It is also noteworthy that cognitive-developmental theory was not specifically developed to understand children's group attitudes in such explicitly competitive intergroup contexts. Some intergroup relationships may be sufficiently competitive that even the most despicable in-group member would be preferred over any out-group member. Given the competitive intergroup context of the present study we might have expected some inhibition of positive evaluations of deviant out-group members or negative evaluations of deviant in-group members, or both. However, despite the strong intergroup differentiation that results from competition, out-group deviants were favored significantly over in-group deviants. This effect is more substantial than that in our previous study that involved a relatively noncompetitive context (Abrams et al., 2003), in which older children showed a significant preference for an in-group normative over an in-group deviant, and an out-group deviant over an outgroup normative, but only a nonsignificant preference for an out-group deviant over an in-group deviant. This difference between the Abrams et al. (2003) and the present research is consistent with evidence in the adult literature that intergroup competition results in larger SGD effects (e.g., Marques, Abrams, \& Serôdio, 2001).

We are also aware that there may be particular types of group membership (e.g., religious denomination) or cultural factors that could encourage or inhibit differential evaluations of members within groups. The present study was conducted in the relatively individualistic context of England. It may be that children in more collectivist cultures are encouraged to treat in-group and out-group deviants differently (see Abrams, Ando, \& Hinkle, 1998; Smith \& Bond, 1994; Triandis, 1995). A further issue is what form we would expect SGD to take with pervasive group memberships such as gender or 
ethnicity. Most previous research has concentrated on in-group biases in judgments of typical members of these groups rather than on comparative judgments of normative and deviant members. We would expect that when these naturally occurring groups are in direct comparison, older children are likely to be more attentive to intragroup differences that are relevant to the distinct norms of each group. This is a potentially useful avenue for future research.

A further limitation is that the measures used in this study were necessarily simpler than those used in research with adults. However, we are reassured that the question-and-response formats were easily understood by the youngest children and were sufficiently sensitive to detect differences in judgments even among those children (e.g., general intergroup biases). In addition, no attempt was made to measure motivational processes or perceptions of subjective validity of the group norms. Future research is needed to examine these variables and more subtle implications of the SGD model, such as reactions to different types of deviant (Abrams et al., 2000) and different types of norm violation (Marques, Abrams \& Serodio, 2001). These issues may require different or more complex measurement techniques to be devised.

\section{Conclusions}

The present findings support the idea that SGD emerge in children later than basic in-group preferences. Children of all ages showed evidence of significant in-group bias, whereas only the older children showed bias in both intergroup and intragroup judgments. There is a developmental strengthening of the relationship between in-group bias and intragroup differential evaluation, both of which may enhance in-group social identity. Taken together, these results are consistent with our developmental model of SGD. As children begin to attend to multiple categories and individuating information they also show evidence of combining the processes of intragroup and intergroup comparison. We found children's evaluations of individual targets were not just influenced by what was said but also by the group membership of the target person. That is, when children pay closer attention to detailed information about individual others, they also integrate such information with their knowledge of a person's group membership and their own social identity. In addition, we found when children understand the implications of deviant behavior within the group and they demonstrate strong identification, SGD emerge most clearly.

There are interesting implications of this research for the way children understand, and respond to, a range of potentially deviant behaviors. In a school a child may be viewed as deviant as a result of bullying, physical differences, overworking, selection of out-group friends, and expression of attitudes that implies movement toward or away from the perceiver's group. Children's understanding of, and reactions to, deviance in an intergroup context appears to change substantially between the ages of 5 and 11. This suggests that strategies for adult intervention (e.g., to prevent victimization) may need to be different for children of different ages.

Our findings show that, by the age of 11, some of the psychological processes that underpin social regulation of the behavior of members of adult groups may be well established. Future research is needed to investigate whether these developmental changes occur in other intergroup contexts (e.g. ethnic, gender, and minimal groups) and to see how intergroup biases may combine with other aspects of social and moral development to affect children's judgments of individuals within groups.

\section{References}

Aboud, F. E. (1988). Children and prejudice. Oxford, England: Blackwell.

Aboud, F. E., \& Amato, M. (2001). Developmental and socialization influences on intergroup bias. In R. Brown \& S. L. Gaertner (Eds.), Blackwell handbook of social psychology: Intergroup processes (pp. 65-85). Oxford, England: Blackwell.

Abrams, D., Ando, K., \& Hinkle, S. (1998). Psychological attachment to the group: Cross-cultural differences in organizational identification and subjective norms as predictors or workers' turnover intentions. Personality and Social Psychology Bulletin, 24, 1027-1039.

Abrams, D., Marques, J. M., Bown, N., \& Dougill, M. (2002). Anti-norm and pro-norm deviance in the bank and on the campus: Two experiments on subjective group dynamics. Group Processes and Intergroup Relations, 5, 163-182.

Abrams, D., Marques, J. M., Bown, N. J., \& Henson, M. (2000). Pro-norm and anti-norm deviance within ingroups and out-groups. Journal of Personality and Social Psychology, 78, 906-912.

Abrams, D., Marques, J. M., Randsley de Moura, G., Hutchison, P., \& Bown, N. J. (in press). The maintenance of entitativity: A subjective group dynamics approach. In V. Y. Yzerbyt, C. M. Judd, \& O. Corneille (Eds.), The psychology of group perception: Contribution to the study of homogeneity, entitativity, and essentialism. Philadelphia: Psychology Press. 
Abrams, D., Rutland, A., Cameron, L., \& Marques, J. M. (2003). The development of subjective group dynamics: When in-group bias gets specific. British Journal of Developmental Psychology, 21, 155-176.

Aiken, L. S., \& West, S. G. (1991). Multiple regression: Testing and interpreting interactions. Thousand Oaks, CA: Sage.

Alvarez, J. M, Ruble, D. N., \& Bolger, N. (2001). Trait understanding or evaluative reasoning? An analysis of children's behavioral predictions. Child Development, 72, $1409-1425$.

Barenboim, C. (1978). The development of recursive and non-recursive thinking about persons. Developmental Psychology, 52, 129-144.

Barenboim, C. (1981). The development of person perception in childhood adolescence: From behavioral comparisons to psychological constructs to psychological comparisons. Child Development, 52, 129-144.

Baron, R. M., \& Kenny, D. A. (1986). The moderatormediator variable distinction in social psychological research: Conceptual, strategic, and statistical considerations. Journal of Personality and Social Psychology, 51, $1173-1182$.

Barrett, M., \& Short, J. (1992). Images of European people in a group of 5-10 year old English schoolchildren. British Journal of Developmental Psychology, 10, 339-363.

Berndt, T. J., \& Heller, K. A. (1986). Gender stereotypes and social inferences: A developmental study. Journal of Personality and Social Psychology, 50, 889-898.

Biernat, M. (1991). Gender stereotypes and the relationship between masculinity and femininity: A developmental analysis. Journal of Personality and Social Psychology, 61, $351-365$.

Bigler, R. S. (1995). The role of classification skill in moderating environmental influences on children's gender stereotyping: A study of the functional use of gender in the classroom. Child Development, 66, 1072-1087.

Bigler, R. S., \& Liben, L. S. (1992). Cognitive mechanisms in children's gender stereotyping: Theoretical and educational implications of a cognitive-based intervention. Child Development, 63, 1351-1363.

Black-Gutman, D., \& Hickson, F. (1996). The relationship between racial attitudes and social-cognitive development in children: An Australian study. Developmental Psychology, 32, 448-456.

Coull, A., Yzerbyt, V. Y., Castano, E., Paladino, M. P., \& Leemans, V. (2001). Protecting the ingroup: Motivated allocation of cognitive resources in the presence of threatening ingroup members. Group Processes and Intergroup Relations, 4, 327-339.

Doyle, A., \& Aboud, F. (1995). A longitudinal study of white children's racial prejudice as a social-cognitive development. Merrill-Palmer Quarterly, 41, 2, 209-228.

Durkin, K., \& Judge, J. (2001). Effects of language and social behavior on children's reactions to foreign people in television. British Journal of Developmental Psychology, $19,597-612$.

Goodman, L. A. (1960). On the exact variance of products. Journal of the American Statistical Association, 55, 708-71.
Hutchison, P., \& Abrams, D. (2003). Ingroup identification moderates stereotype change in reaction to ingroup deviance. European Journal of Social Psychology, 33, 497-506.

Judd, C. M., Kenny, D. A., \& McClelland, G. H. (2001). Estimating and testing mediation and moderation in within subjects designs. Psychological Methods, 6, $115-134$.

Katz, P. A. (1976). The acquisition of racial attitudes in children. In P. A. Katz (Ed.), Towards the elimination of racism (pp. 125-154). New York: Pergamon.

Katz, P. A., Sohn, M., \& Zalk, S. R. (1975). Perceptual concomitants of racial attitudes in urban grade-school children. Developmental Psychology, 11, 135-144.

Killen, M., Crystal, D. S., \& Watanabe, H. (2002). Japanese and American children's evaluations of peer exclusion, tolerance of differences, and prescriptions for conformity. Child Development, 73, 1788-1802.

Killen, M., \& Stangor, C. (2001). Children's social reasoning about inclusion and exclusion in gender and race peer groups contexts. Child Development, 72, 174-186.

Kurzban, R., \& Leary, M. R. (2001). Evolutionary origins or stigmatization: The functions of social exclusion. Psychological Bulletin, 127, 187-208.

Lambert, W. E., \& Klineberg, O. (1967). Children's views of foreign peoples: A cross-national study. New York: Appleton-Century-Crofts.

Levine, J. M. (1989). Reaction to opinion deviance in small groups. In P. B. Paulus (Ed.), Psychology of group influence (2nd ed., pp. 187-231). Hillsdale, NJ: Erlbaum.

Livesley, W. J., \& Bromley, D. B. (1973). Person perception in childhood $\mathcal{E}$ adolescence. Oxford, England: Wiley.

MacKinnon, D. P., Warsi, G., \& Dwyer, J. H. (1995). A simulation study of mediated effect measures. Multivariate Behavioral Research, 30, 41-62.

Marques, J. M., Abrams, D., Pàez, D., \& Hogg, M. A. (2001). Social categorization, social identification, and rejection of deviant group members. In M. A. Hogg \& R. S. Tindale (Eds.), Blackwell handbook of social psychology (Vol. 3): Group processes (pp. 400-424). Oxford, England: Blackwell.

Marques, J. M., Abrams, D., Pàez, D., \& Martinez-Taboada, C. (1998). The role of categorization and in-group norms in judgments of groups and their members. Journal of Personality and Social Psychology, 75, 976-988.

Marques, J. M., Abrams, D., \& Serôdio, R. G. (2001). Being better by being right: Subjective group dynamics and derogation of in-group deviants when generic norms are undermined. Journal of Personality and Social Psychology, 81, 436-447.

Marques, J. M., \& Pàez, D. (1994). The "black sheep effect": Social categorization, rejection of in-group deviates, and perception of group variability. In W. Stroebe \& $\mathrm{M}$. Hewstone (Eds.), European review of social psychology (Vol. 5, pp. 38-68). Chichester, England: Wiley.

Marques, J. M., Yzerbyt, V. Y., \& Leyens, J. -P. (1988). The black sheep effect: Judgmental extremity towards ingroup members as a function of ingroup identification. European Journal of Social Psychology, 18, 1-16. 
Martin, C. L. (1989). Children's use of gender-related information in making social judgments. Developmental Psychology, 25, 80-88.

Nesdale, D. (2001). Development of prejudice in children. In M. Augoustinos \& K. J. Reynolds (Eds.), Understanding prejudice, racism and social conflict. London: Sage.

Peevers, B. H., \& Secord, P. F. (1973). Developmental changes in attribution of descriptive concepts to persons. Journal of Personality and Social Psychology, 27, $120-128$.

Piaget, J., \& Weil, A. (1951). The development in children of the idea of the homeland and of relations with other countries. International Social Science Bulletin, 3, 561-578.

Powlishta, K. K. (1995). Intergroup processes in childhood: Social categorization and sex role development. Developmental Psychology, 31, 781-788.

Powlishta, K., Serbin, L. A., Doyle, A., \& White, D. R. (1994). Gender, ethnic, and body type biases: The generality of prejudice in childhood. Developmental Psychology, 30, 526-536.

Quintana, S. M. (1994). A model of ethnic perspectivetaking ability applied to Mexican-American children and youth. International Journal of Intercultural Relations, $18,419-448$.

Quintana, S. M. (1998). Children's developmental understanding of ethnicity and race. Applied and Preventative Psychology, 7, 27-45.

Quintana, S. M. (1999). Role of perspective-taking abilities and ethnic socialization in development of adolescent ethnic identity. Journal of Research on Adolescence, 19, $161-184$.

Ruble, D. N., Alvarez, J., Bachman, M., \& Cameron, J. (in press). The development of a sense of "we": The emergence and implications of children's collective identity. In M. Bennett \& F. Sani (Eds.), The development of social self. East Sussex, England: Psychology Press.

Ruble, D. N., \& Dweck, C. S. (1995). Self-conceptions, person conceptions, and their development. In $\mathrm{N}$. Eisenberg (Ed.), Review of personality and social psychol- ogy: Social development (Vol. 15, pp. 109-139). Thousand Oaks, CA: Sage.

Rutland, A. (1999). The development of national prejudice, in-group favoritism and self stereotypes in British children. British Journal of Social Psychology, 38, 55-70.

Schachter, S. (1951). Deviation, rejection and communication. Journal of Abnormal and Social Pscyhology, 46, $190-207$.

Selman, R. L. (1971). Taking another's perspective: Roletaking development in early childhood. Child Development, 42, $1721-1734$.

Selman, R. L. (1980). The growth of interpersonal understanding: Development and clinical analyses. San Diego, CA: Academic Press.

Serbin, L. A., \& Sprafkin, C. (1986). The salience of gender and the process of sex typing in three- to seven-year-old children. Child Development, 57, 1188-1199.

Smith, P. B., \& Bond, M. H. (1994). Social psychology across cultures: Analysis and perspectives. Boston: Allyn \& Bacon.

Tajfel, H. (1981). Human groups and social categories: Studies in social psychology. Cambridge, England: Cambridge University Press.

Tajfel, H., \& Turner, J. C. (1986). The social identity theory of intergroup behavior. In S. Worchel \& W. G. Austin (Eds.), The psychology of intergroup relations (pp. 7-24). Chicago: Nelson-Hall.

Triandis, H. C. (1995). A theoretical framework for the study of diversity. In H. M. Chemers \& S. Oskamp (Eds.), Diversity in organizations: New perspectives for a changing workplace. Claremont Symposium on Applied Social Psychology 8, 11-36.

Yee, M. D., \& Brown, R. (1994). The development of gender differentiation in young children. British Journal of Social Psychology, 33, 183-196.

Zdaniuk, B., \& Levine, J. M. (2001). Group loyalty: Impact of members' identification and contributions. Journal of Experimental Social Psychology, 37, 502-509. 